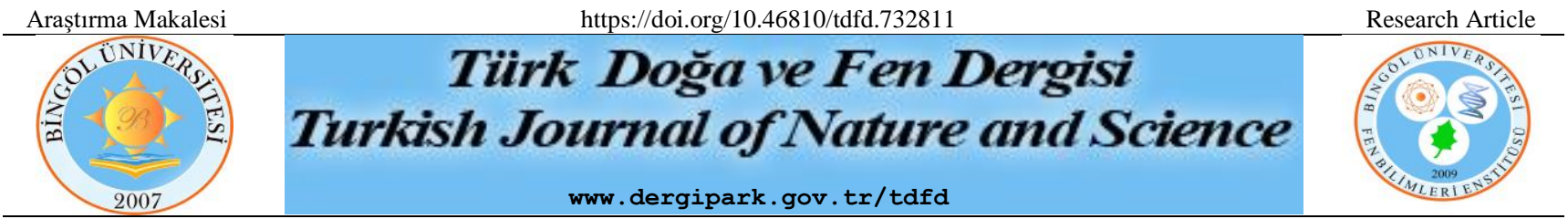

Field-Dependent Charge Collection Model for Thin Film Organic Photovoltaics

\author{
Hasan KURT ${ }^{1^{*}}$ \\ ${ }^{1}$ İstanbul Medipol University, School of Engineering and Natural Sciences, İstanbul, Turkey \\ Hasan Kurt ORCID No: 0000-0002-1677-644X \\ *Corresponding author: hasankurt@medipol.edu.tr
}

(Alınıș: 06.05.2020, Kabul: 15.09.2020, Online Yayınlanma: 23.10.2020)

\begin{abstract}
Keywords
Charge

collection,

Organic

Photovoltaics,

Charge carrier

Abstract: In this study, a unified charge collection model is developed using an optical cavity dependent charge carrier generation and non-uniform built-in electric field distribution within a bulk heterojunction photovoltaic device. The charge collection model relies on the experimental inputs related to the charge carrier dynamics such as mobilities of charge carriers, recombination lifetime, and junction width of charge carrier species. Optical cavity modes and field strength were calculated using the experimental variable angle ellipsometry analysis of individual components of the devices. In order to evaluate the model, ambient processed PCDTBT:PC ${ }_{71}$ BM based conventional and inverted derive architectures were utilized to underline the effect of unintentional doping and distinct optical cavity modes. The simulated external quantum efficiency and shortcircuit current density profiles from the model were compared to the experimental results with differing active layers thicknesses and device architectures. The proposed charge collection model presented a high degree of correlation with the experimental results and underlined its validity for further application on other types of organic photovoltaic devices.
\end{abstract}

\title{
İnce Film Organik Fotovoltaikler İçin Alana Bağlı Yük Toplama Modeli
}

\section{Anahtar \\ Kelimeler Yük toplama, Organik fotovoltaik, Yük Taşıyıcı}

\begin{abstract}
Öz: Bu çalışmada, bir bulk heteroeklem fotovoltaik cihaz içinde optik kaviteye bağlı yük taşıyıcı üretimini ve homojen olmayan elektrik alan dağılımını gözönünde bulunduran birleştirilmiş yük toplama modeli geliştirilmiştir. Yük toplama modeli; yük taşıyıcıların mobiliteleri, rekombinasyon ömrü ve yük taşıyıcı türlerin bağlantı genişliği gibi yük taşıyıcı dinamiği ile ilgili deneysel girdilere dayanmaktadır. Optik kavite modları ve alan şiddeti, cihazların ayrı ayrı bileşenlerinin deneysel olarak değişken açılı elipsometri analizi kullanılarak hesaplanmıştır. Modeli değerlendirmek için, istenmeyen katkılama ve farklı optik kavite modlarının etkisinin altını çizmek için hava ortamında üretilmiş PCDTBT: PC71BM tabanlı geleneksel ve ters organik fotovoltaik mimariler karşılaştırmalı olarak kullanılmıştır. Modelden simüle edilen harici kuantum verimliliği ve kısa devre akım yoğunluğu profilleri, farklı aktif katman kalınlıkları ve cihaz mimarileri ile yapılan deneysel sonuçlarla karşılaştırılmıştır. Önerilen yük toplama modeli, deney sonuçları ile yüksek derecede örtüşme göstererek diğer organik fotovoltaik aygıtlarda da uygulaması için geçerliliğinin altını çizmiştir.
\end{abstract}

\section{INTRODUCTION}

Thin-film bulk heterojunction organic photovoltaics remains to be achieving a new set of record power conversion efficiency in the last 20 years reaching up from $2.5 \%$ to $18.2 \%$ [1,2]. Even though intrinsic disadvantages of organic photovoltaics such as structural/electronic disorder, low dielectric constant leading to diminished charge separation efficiency, and limited charge carrier mobility with respect to inorganic counterparts, OPVs remain to be surviving in such a competitive scientific photovoltaics field of study.

Diminished charge collection efficiency directly lowers the fill factor and short circuit current density of an OPV. In theory, organic photovoltaic devices are considered to be doping-free and are p-i-n type, unlike their inorganic photovoltaics. Work function dependent selective interlayers drive the charge carriers to their respective electrodes [3]. However, recent impedance spectroscopy based studies underline unintentional doping leading to non-uniform electric field distribution 
within the intrinsic bulk heterojunction layer [4-6]. In order to analyze this phenomenon, the parallel capacitor model is widely utilized to probe the non-uniform electric field distribution due to unintended dopingrelated space-charge densities and highly asymmetric charge carrier mobilities $[7,8]$. Even though these studies focus on the non-uniform electric field due to unintended doping and asymmetric charge carrier mobilities, overall charge generation profiles due to the optical cavity nature of these thin-film organic photovoltaics.

In this paper, we combined the optical cavity dependent local charge carrier generation and non-uniform electric field dependent charge carrier collection efficiency in a unified model. Air-processed PCDTBT:PC ${ }_{71} B M$ based organic photovoltaics were utilized as to stress better the effect of the highly asymmetric charge carrier mobilities and unintentional doping (mainly processing conditions related). Furthermore, conventional $\mathrm{p}-\mathrm{i}-\mathrm{n}$ and inverted $\mathrm{n}$ i-p devices geometries were investigated to underline the differing optical cavity modes due to the difference in optical constants of the charge selective interlayers and top metal electrodes.

\section{EXPERIMENTAL PROCEDURES}

All solvents and reagents were obtained from Ossila Ltd. and Sigma-Aldrich unless specified. All devices were fabricated in ambient cleanroom conditions. The conventional device structures were ITO/PEDOT :PSS/PCDTBT:PC ${ }_{71} \mathrm{BM}(1: 4) / \mathrm{LiF} / \mathrm{Al}$, as described in the earlier work [9-11]. The inverted device structures were ITO/ZnO/PCDTBT:PC ${ }_{71} \mathrm{BM}(1: 4) / \mathrm{MoO}_{3} / \mathrm{Ag}$. Patterned ITO substrates were diligently cleaned using Hellmanex, deionized water, acetone, methanol, and isopropanol in an ultrasonic bath for $15 \mathrm{~min}$ each. The substrates were dried under nitrogen stream and treated with UV-ozone for $30 \mathrm{~min}$ before use. A thin layer (ca. $30 \mathrm{~nm}$ ) of PEDOT:PSS (Heraeus Clevios ${ }^{\mathrm{TM}} \mathrm{P}$ VP AI 4083, filtered at $0.45 \mu \mathrm{m}$ syringe filter) was spin-coated at $4000 \mathrm{rpm}$ and baked at $150^{\circ} \mathrm{C}$ for $15 \mathrm{~min}$. For inverted architecture, $\mathrm{ZnO}$ precursor solution was prepared using $1 \mathrm{~g}$ of zinc acetate dihydrate and $0.28 \mathrm{~g}$ monoethylamine in $10 \mathrm{ml}$ of 2-methoxyethanol. The solution is hydrolyzed under temperature of $60^{\circ} \mathrm{C}$ for 12 hours exposed to air. A thin layer (ca. $30 \mathrm{~nm}$ ) of $\mathrm{ZnO}$ was spincoated at $3000 \mathrm{rpm}$ and annealed at $200^{\circ} \mathrm{C}$ for $60 \mathrm{~min}$. $20 \mathrm{mg} \cdot \mathrm{mL}^{-1}$ chlorobenzene solution of PCDTBT:PC ${ }_{71} \mathrm{BM}$ is deposited on respective transport layers by spin coating at different rotation speeds and durations to obtain active layer thickness from $40 \mathrm{~nm}$ to $290 \mathrm{~nm}$. For electrical back contact deposition, the substrates were placed into the shadow mask carrier to patterning the OPV active area $\left(4.5 \mathrm{~mm}^{2}\right)$ and placed into the thermal evaporator chamber and pumped down to a pressure of ca. $2 \times 10^{-6} \mathrm{mbar}$. LiF/Al $(2 \mathrm{~nm} / 100 \mathrm{~nm})$ and $\mathrm{MoO}_{3} / \mathrm{Ag}(5 \mathrm{~nm} / 100 \mathrm{~nm})$ layers were thermally deposited onto the active layer of the substrates for conventional and inverted architecture respectively. After electrode deposition, the substrates were annealed at $80^{\circ} \mathrm{C}$ under vacuum. Finally, the devices were encapsulated with UV-curable epoxy. The short-circuit current density characteristics of encapsulated photovoltaic devices were measured using a Keithley 2401 source meter under AM 1.5G solar irradiation at $100 \mathrm{~mW} / \mathrm{cm}^{2}$

Impedance measurements were completed using Solartron 1260 Impedance/Gain-phase Analyzer at a fixed frequency of $10 \mathrm{kHz}$; AC perturbation of $10 \mathrm{mV}$ and DC bias of $0.2-1.4 \mathrm{~V}$. A halogen lamp were used to illuminate the devices. The lamp intensity is adjusted to coincide with the short circuit density of the devices under AM1.5G illumination.

Refractive index profiles of transparent conductor - ITO -, hole transporting layers - PEDOT:PSS and $\mathrm{MoO}_{3}-$, electron transporting layer $-\mathrm{ZnO}-$ and active layer PCDTBT:PC ${ }_{71} \mathrm{BM} \mathrm{(1:4)} \mathrm{-} \mathrm{were} \mathrm{measured} \mathrm{using} \mathrm{a}$ variable angle spectroscopic ellipsometer (J.A. Woollam Co. VASE) and plotted in Figure 4. The refractive index profiles of $\mathrm{LiF}$ and $\mathrm{Al}$ were retrieved from the works of $\mathrm{Li}$ et al. and Rakic et al. [12,13].

\section{DEVICE SIMULATION}

The capacitance of planar thin-film organic photovoltaic $(C)$ can be directly approximated to a parallel plate capacitor

$$
C=\frac{\varepsilon_{0} \varepsilon_{r} A}{w}
$$

where $\varepsilon_{0}$ is the permittivity of space, $\varepsilon_{r}$ is the relative permittivity of the bulk heterojunction.

$$
C^{-2}(V)=\frac{2}{q \varepsilon_{0} \varepsilon_{r} A^{2} N_{A}}\left(V_{b i}-V\right)
$$

where $V_{b i}$ is the built-in (flat-band) potential of the bulk heterojunction, $V$ is the applied voltage, $q$ is the elementary charge, $A$ is the cross-sectional area of the device and $N_{A}$ is the doping concentration. $V_{b i}$ can be extracted from $x$-axis intercept voltage of $C^{-2}$ vs $V$ plot. The slope of $C^{-2}$ can be used to extract the unintended doping concentration as follows

$$
\frac{d C^{-2}(V)}{d V}=\frac{-2}{q \varepsilon_{0} \varepsilon_{r} A^{2} N_{A}}
$$

Given that $N_{A}$ and $V_{b i}$ is extracted from the capacitance characteristics of planar organic photovoltaics, the depletion width of the charge carrier species can be calculated as the following equation

$$
w=\sqrt{\frac{2 \varepsilon_{0} \varepsilon_{r}\left(V_{b i}-V\right)}{q N_{A}}}
$$

Since Mott-Schottky plot can only probe the higher mobility charge carriers, the depletion width for the lower mobility species - holes- is approximated as the half of the depletion width of the electrons $\left(w_{e}=2 \times\right.$ $w_{h}$ ) as $80 \mathrm{~nm}$ and $40 \mathrm{~nm}$, respectively. 
In order to simulate the non-uniform electric field inside the bulk heterojunction, we used quadratic band bending approximation to extract the electric field for electrons $\left(V_{e}\right)$

$$
V_{e}(x)=\frac{\left(x-w_{e}\right)^{2}}{w_{e}^{2}}\left(V_{b i}-V\right) \quad 0<x<w_{e}
$$

where $x$ is the distance from the cathode of the organic photovoltaics. For the electric field for holes $\left(V_{h}\right)$ was approximated as the following

$$
V_{h}(x)=\frac{\left(x-\left(d-w_{h}\right)\right)^{2}}{w_{h}^{2}}\left(V_{b i}-V\right) w_{h}<x<d
$$

where $d$ is the thickness of the bulk heterojunction layer. The non-uniform electric field approximation is converted into non-uniform electric field distribution inside the BHJ layer using the first derivative of the $V_{e}$ with respect to $x$. Position dependent electric field components $\left(E_{e, h}(x)\right)$ are inserted into the positiondependent drift length equation for each charge carrier species as the following

$$
L_{e, h}(x)=\mu_{e, h} \tau E_{e, h}(x)
$$

where $\mu_{e, h}$ is the mobility of the respective charge carrier species and $\tau$ is the charge carrier lifetime recombination lifetime. For this study, we neglected the position-dependent mobility as it is highly dependent on the nanoscale morphology of the bulk heterojunction and phase distribution of the donor and acceptor species. For electron mobility, $\mu_{e}$ is taken as $1.0 \times 10^{-3} \mathrm{~cm}^{2}$. $V^{-1} s^{-1}$. For hole mobility, $\mu_{h}$ is taken as $5.0 \times$ $10^{-5} \mathrm{~cm}^{2} \cdot V^{-1} \mathrm{~s}^{-1}$. Charge carrier lifetime $(\tau)$ is set to $2.0 \times 10^{-5} S$. The position-dependent drift lengths later converted into position-dependent charge carrier collection efficiency - collection probability - for each charge carrier species as follows

$$
\eta_{e c c}(x)=e^{-\frac{x}{L_{e}(x)}} \quad \eta_{h c c}(x)=e^{-\frac{d-x}{L_{h}(x)}}
$$

The position-dependent charge collection efficiency for charge carrier species is calculated for a set of bulk heterojunction layer thicknesses from $40 \mathrm{~nm}$ to $290 \mathrm{~nm}$ as shown in Figure 1 and 2 for inverted and conventional device architectures.

For both device structures, s- and p-polarized plane waves were incident to the normal to the device layers from soda-lime glass substrate layer. Indium tin oxide layer was set to fixed to $100 \mathrm{~nm}$ thickness as the ITO coated glass substrate in OPV fabrication. PEDOT:PSS hole transport layer and $\mathrm{ZnO}$ electron transport layers were set to $30 \mathrm{~nm}$ in junction with fabrication procedures. Bulk heterojunction layer thickness of PCDTBT:PC ${ }_{71} \mathrm{BM}$ (1:4) was varied between $40 \mathrm{~nm}$ and $290 \mathrm{~nm}$ to identify the thin-film cavity modes. Top electrodes layers were set to $2 \mathrm{~nm}$ thick $\mathrm{LiF}$ and subsequent $100 \mathrm{~nm}$ thick $\mathrm{Al}$ for conventional architecture and $5 \mathrm{~nm}$ thick $\mathrm{MoO}_{3}$ and subsequent 100 $\mathrm{nm}$ thick $\mathrm{Ag}$ in parallel with the fabrication parameters.
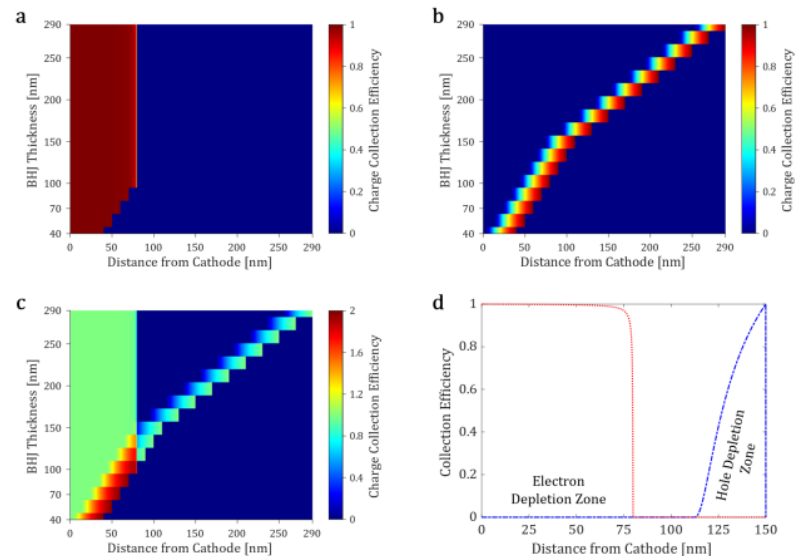

Figure 1. For the inverted architecture of PCDTBT:PC ${ }_{71} \mathrm{BM} \mathrm{BH}$ device, a) electron collection efficiency profile, b) hole collection efficiency profile, c) combined charge collection efficiency with respect to distance from the cathode and $\mathrm{BHJ}$ thickness, and d) charge collection efficiency profile for $150 \mathrm{~nm}$ thick inverted BHJ device architecture.
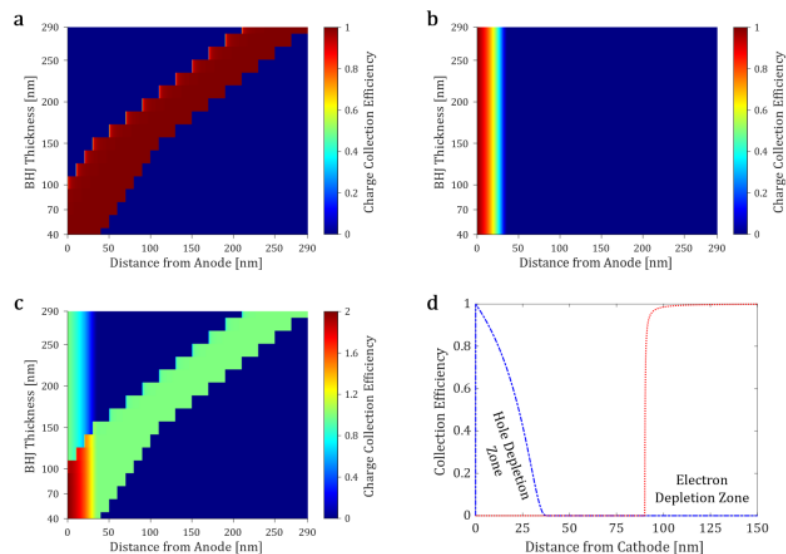

Figure 2. For the conventional architecture of PCDTBT:PC ${ }_{71} \mathrm{BM} \mathrm{BHJ}$ device, a) electron collection efficiency profile, b) hole collection efficiency profile, c) combined charge collection efficiency with

\begin{tabular}{|c|c|c|}
\hline $\mathrm{Al}$ & \multirow{3}{*}{$\begin{array}{c}100 \mathrm{~nm} \\
2 \mathrm{~nm} / 5 \mathrm{~nm} \\
40-290 \mathrm{~nm}\end{array}$} & $\mathrm{Ag}$ \\
\hline $\mathrm{LiF}$ & & $\mathrm{MoO}_{\mathrm{x}}$ \\
\hline PCDTBT:PC ${ }_{71}$ BM (1:4) & & PCDTBT:PC ${ }_{71}$ BM (1:4) \\
\hline PEDOT:PSS & \multirow{3}{*}{$\begin{array}{l}30 \mathrm{~nm} \\
100 \mathrm{~nm}\end{array}$} & $\mathrm{ZnO}$ \\
\hline ITO & & ITO \\
\hline Soda Lime Glass & & Soda Lime Glass \\
\hline
\end{tabular}
respect to distance from the anode and BHJ thickness, and d) charge collection efficiency profile for $150 \mathrm{~nm}$ thick conventional BHJ device architecture.

Figure 3. The conventional and inverted device architectures are represented left and right respectively, which are used in device fabrication and optical device simulations.

Absorbed optical power per unit volume of the bulk heterojunction $\left(P_{a b s}\right)$ layer was calculated real part of the divergence of the Poynting vector $(\boldsymbol{P})$, which can be reduced to the following equation 


$$
\begin{aligned}
P_{a b s}(x, \lambda)=-\frac{1}{2} \mathfrak{R} & \{\nabla \cdot \boldsymbol{P}(x, \lambda)\} \\
= & -\frac{1}{2} \omega|\boldsymbol{E}(x, \lambda)|^{2} \Im\left\{\varepsilon_{b h j}(\lambda)\right\}
\end{aligned}
$$

where $\boldsymbol{E}$ is the electric field vector, $\omega$ is the wavelength of the incoming light and $\mathfrak{J}\left\{\varepsilon_{b h j}(\lambda)\right\}$ is the imaginary part of the dielectric constant of the bulk heterojunction. Subsequently, $P_{a b s}$ can be converted into generation rate function $g(x, \lambda)$ and integrated into the positiondependent generation rate $(G(x))$ over all angular frequencies as shown below

$$
g(x, \omega)=\frac{P_{a b s}(x, \lambda)}{h c} \lambda \quad G(x)=\int g(x, \lambda) d \lambda
$$

where $h c / \lambda$ designates the energy of a photon with an angular frequency of $\lambda$.
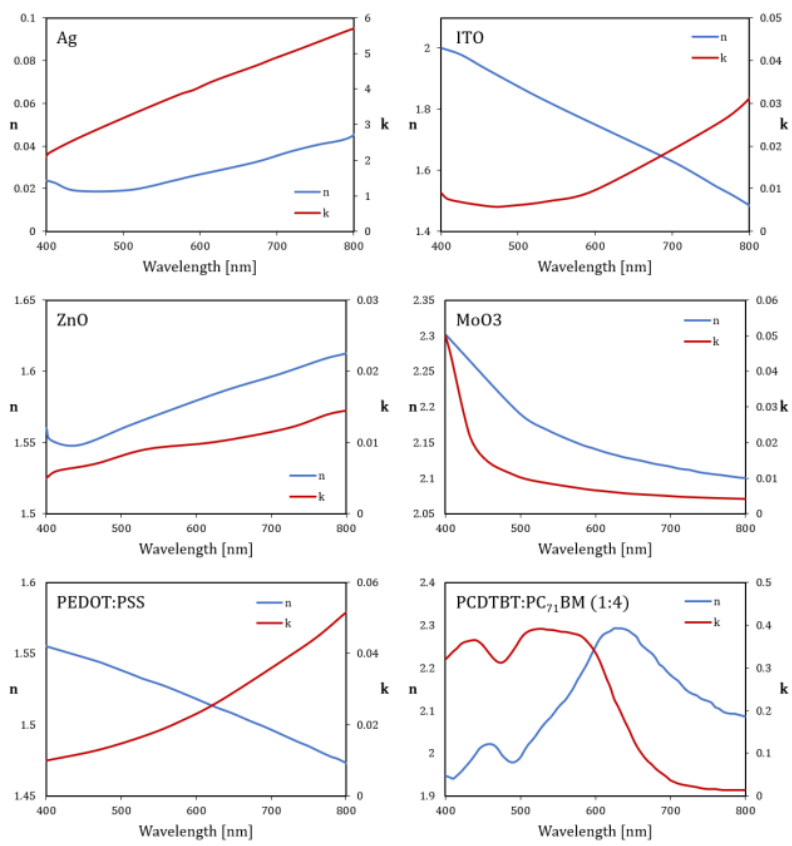

Figure 4. Refractive index profiles of transparent conductor - ITO -, hole transporting layers - PEDOT:PSS and $\mathrm{MoO}_{3}-$, electron transporting layer $-\mathrm{ZnO}$ - and active layer - PCDTBT:PC ${ }_{71} \mathrm{BM}(1: 4)$.

The external quantum efficiency of the simulated devices was calculated using the wavelength and position-dependent generation rate function and combined electron/hole charge carrier collection efficiency over the device thickness as shown below

$$
E Q E(\omega)=\int_{0}^{d} g(x, \lambda) \frac{\eta_{e c c}(x)+\eta_{h c c}(x)}{2} d x
$$

For calculation, the short circuit current density $\left(J_{s c}\right)$, multiplication of wavelength-dependent external quantum efficiency ( $E Q E(\lambda))$ and wavelengthdependent solar irradiation $(S(\lambda))$ was integrated over all wavelengths.

$$
J_{s c}=\int \frac{q \lambda}{h c} E Q E(\lambda) S(\lambda) d \lambda
$$

\section{RESULTS AND DISCUSSION}

Due to the differing trends in refractive index profiles of $\mathrm{ZnO}$ and PEDOT:PSS transport layer pairs and of $\mathrm{MoO}_{3} / \mathrm{Ag}$ and $\mathrm{LiF} / \mathrm{Al}$ top electrode pairs in device architectures, the light intensity profile within the active layer differ significantly. As it has been shown in Figure 5 , both device architectures support three different cavity modes in their BHJ. However, cavity modes do not merge into a combined mode in thicker conventional devices. In the conventional device, wavelengthdependent local generation rate, $g(x, \lambda)$, coalesces in the front of the device - ITO anode - around $350 \mathrm{~nm}, 430$ $\mathrm{nm}$, and $525 \mathrm{~nm}$ peak wavelengths. The predominantly cavity mode of $430 \mathrm{~nm}$ in devices with a thickness of 4060 later abruptly diminishes and does not contribute to the generation rate in thicker devices. In contrast, cavity mode 1 and 2 of inverted device later merged into a supermode as the BHJ thickness increases while the $3^{\text {rd }}$ cavity mode remains to be significantly strong around the band of 550-600 $\mathrm{nm}$. Also, inverted devices can support the cavity modes close to both electrodes of the device resulting in a more uniform distribution of charge carriers within BHJ. Different cavity modes due to the top electrode where it is $\mathrm{LiF}(2 \mathrm{~nm}) / \mathrm{Al}(100 \mathrm{~nm})$ for conventional devices and $\mathrm{MoO}_{3}(5 \mathrm{~nm}) / \mathrm{Ag}(100 \mathrm{~nm})$ for inverted devices. For the spectral region of interest (350-800 $\mathrm{nm}), \mathrm{Ag}$ shows an average refractive index below 0.06. On the other hand, $\mathrm{Al}$ shows a refractive index starting from 0.3 at $350 \mathrm{~nm}$, and exponentially increases to 2.37 at $800 \mathrm{~nm}$. Fabry-Perot cavity modes shift to higher modes as the gap increases between reflectors.

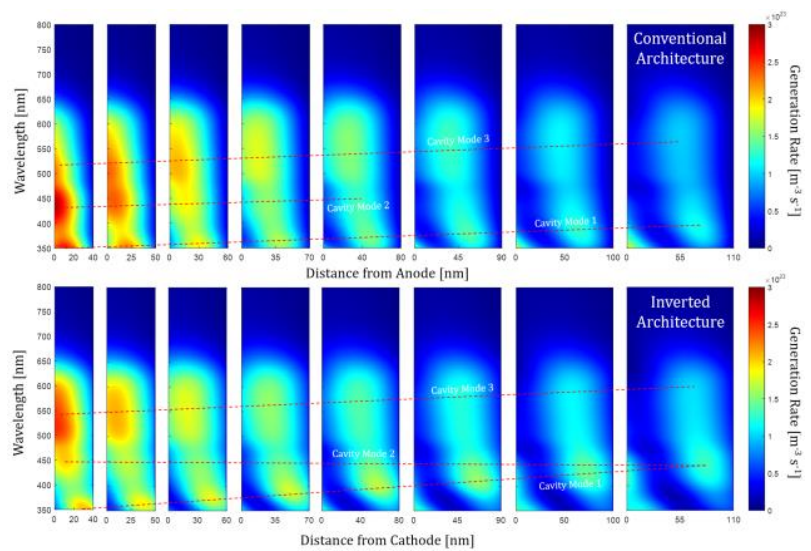

Figure 5. The simulated local generation rate, $g(x, \lambda)$, for conventional and inverted devices with a thickness of 40-110 $\mathrm{nm}$ over the wavelength range of $350-800 \mathrm{~nm}$

As can be seen from the simulated generation rate profile from AM1.5G solar spectrum in Figure 6, the total generation is reduced into two main cavity modes inside BHJ. The main generation cavity mode 1 in inverted architecture shows a closer profile to the top electrode than the conventional architecture. The simulated generation profiles are later converted into an external quantum efficiency profile over a range of $\mathrm{BHJ}$ thicknesses. Since external quantum efficiency is a strong function of charge collection efficiency, the 
perfect collection case was plotted as $n_{c c}(x, \lambda)=1$ in the upper column and the modeled collection case was plotted as $\mathrm{n}_{\mathrm{cc}}(\mathrm{x}, \lambda)$ as depicted in Figure 1 and Figure 2. The modeled external quantum efficiency profile of conventional architecture showed a dominant peak in the wavelength range of $500-600 \mathrm{~nm}$ and the thickness range of $40-70 \mathrm{~nm}$. On the other hand, two dominant peaks were observed in inverted architecture. The most dominant EQE peak was in the wavelength range of 500 $-575 \mathrm{~nm}$ and the thickness range of $40-70 \mathrm{~nm}$. The secondary EQE peak emerged in the wavelength range of $375-425 \mathrm{~nm}$ and the thickness range of $60-80 \mathrm{~nm}$.

The charge collection model was later compared with the experimental devices with both architectures in Figure 7 and Figure 8. The external quantum efficiency profiles of both simulated/modeled and experimental conventional device architectures show high consistency in the wavelength range of $500-700 \mathrm{~nm}$. However, the discrepancies in the wavelength range of $350-450 \mathrm{~nm}$ were evident in OPVs with 50 and $70 \mathrm{~nm}$ active layer thickness. The difference between modeled and simulated was believed to be emerged due to the nonuniformity of active layer thickness for thin devices. As the thin film uniformity plays a more predominant role in the optical properties of a thin film in thinner devices. In the inverted architecture, the charge collection model shows a better correlation with the experimental devices than conventional architecture. The discrepancies in near-UV and blue regions were exhibited less predominantly as the electron transport $\mathrm{ZnO}$ layer can accommodate a better surface roughness due to its moderately porous nature [14].
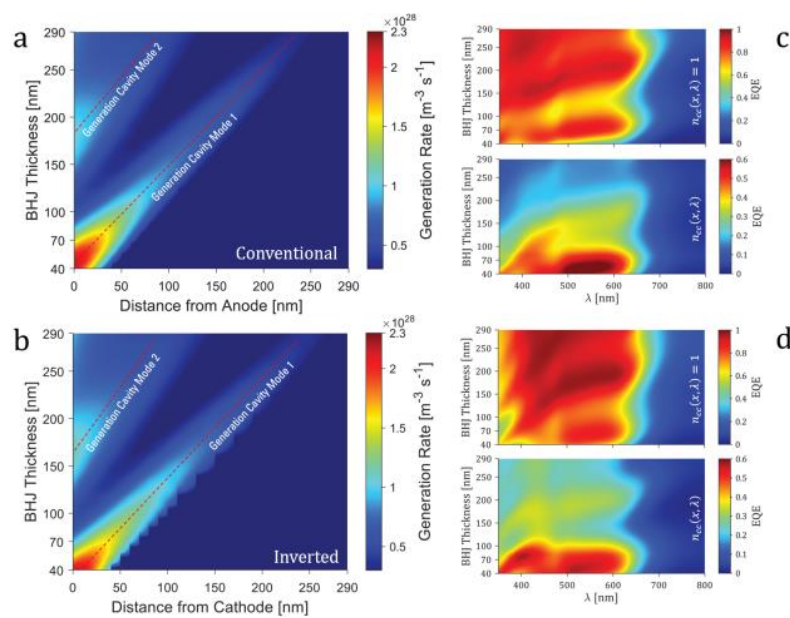

Figure 6. The simulated generation rate profile within the active layers of conventional (a) and inverted (b) device structures depending on the thickness of the PCDTBT:PC ${ }_{71} \mathrm{BM}$ (1:4) bulk heterojunction under AM1.5G illumination. The simulated external quantum efficiency profiles of conventional (c) and inverted (d) PCDTBT:PC ${ }_{71} \mathrm{BM}$ OPVs for perfect charge carrier collection $\left(\mathrm{n}_{\mathrm{cc}}=1\right)$ (upper) and modeled charge carrier collection $\left(\mathrm{n}_{\mathrm{cc}}(\mathrm{x}, \lambda)\right)$ which is a function of position within the active layer and wavelength of the incident illumination.
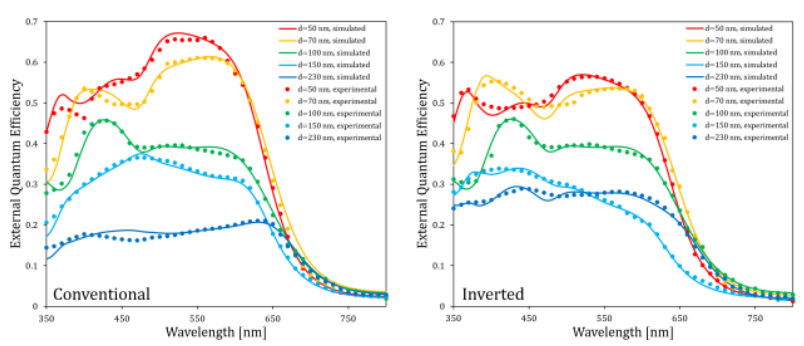

Figure 7. The comparison of external quantum efficiency profiles of modeled PCDTBT:PC ${ }_{71} \mathrm{BM}$ OPVs (solid lines) and experimental devices (filled circles) over the wavelength range of $350 \mathrm{~nm}$ and 800 $\mathrm{nm}$ for conventional (left) and inverted (right) device architectures.

In line with the earlier remark, generation rate distributions of both devices coalesce on the bottom electrode (PEDOT:PSS for conventional, $\mathrm{ZnO}$ for inverted). As the collection efficiency of electrons in devices below the depletion width of $80 \mathrm{~nm}$ reaches unity, as shown in Figures 1 and 2. On the contrary, the collection efficiency of holes is comparatively more limited in range and drastically lower as the distance from the electrode increases. Since exciton generation rate peaks at the vicinity of the bottom electrodes, conventional devices architecture collect a higher number of hole charge carriers than the top electrode of the inverted device where the generation rate is considerably lower. In short, the collection efficiency of electrons does not show any difference between conventional and inverted device architecture in active layer thickness below $80 \mathrm{~nm}$. The hole charge collection depends on the distance from the cathode and exhibits lower depletion $(\sim 40 \mathrm{~nm})$, and conventional architecture shows a higher amount of exciton generation in the vicinity of the cathode. Thus, the difference in efficiency originates from the combination of the charge generation profile and hole charge collection efficiency.

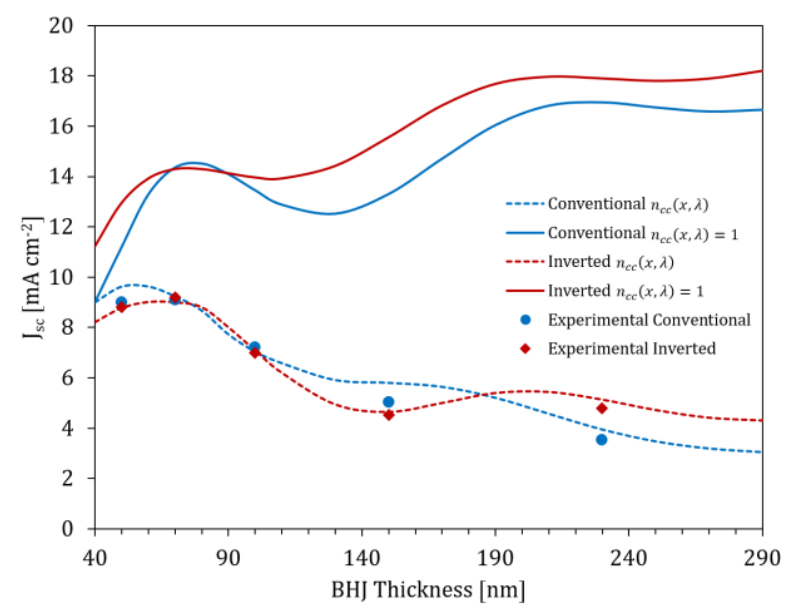

Figure 8. The comparison of short circuit current density $\left(\mathrm{J}_{\mathrm{sc}}\right)$ of PCDTBT:PC ${ }_{71} \mathrm{BM}$ OPV devices with perfect charge carrier collection (solid lines) and modeled charge carrier collection profile (dashed lines) for both device architectures. The experimental results for PCDTBT:PC ${ }_{71} \mathrm{BM}$ OPVs with BHJ thickness of 50, 70, 100, 150, and $230 \mathrm{~nm}$ are overlaid as filled circles and diamonds.

Considering the higher external quantum efficiency profile of conventional architecture, one would expect a higher short circuit current density $\left(J_{s c}\right)$ profile in experimental devices. However, conventional architecture only surpasses invented counterpart only a 
thickness of 50 and $150 \mathrm{~nm}$ as the charge collection model predicated. According to our model, optimal short circuit current density was expected to be around $55-60$ $\mathrm{nm}$ thickness and $70-80 \mathrm{~nm}$ for conventional and inverted architectures, respectively. The suggested model also predicted $J_{s c}$ successfully at $150 \mathrm{~nm}$ and 230 nm thick devices.

\section{CONCLUSION}

We proposed a simplified charge collection model for predicting the performance of bulk heterojunction photovoltaics, relying on the capacitance-voltage characteristics of the bulk heterojunction and optical cavity modes. The suggested model successfully predicted the performance and external quantum efficiency profiles of conventional and inverted PCDTBT:PC ${ }_{71} B M$ OPVs. The simplified model offers a robust prediction of photovoltaic performance at high accuracy since it relies on the initial experimental $\mathrm{C}-\mathrm{V}$ results and refractive index profiles. The model can be also be further developed for other photovoltaic performance factors such as open-circuit voltage, fill factor, and $\mathrm{J}-\mathrm{V}$ characteristics.

\section{Acknowledgment}

Financial support is acknowledged from the Scientific and Technological Research Council of Turkey (TÜBİTAK) for Project No. 217M456. The author is grateful to Sabanc1 University and Sabancı University Nanotechnology Research and Application Center (SUNUM) for access to cleanroom facilities.

\section{REFERENCES}

[1] Brabec CJ, Sariciftci NS, Hummelen JC. Plastic Solar Cells. Adv Funct Mater 2001;11:15-26.

[2] Liu Q, Jiang Y, Jin K, Qin J, Xu J, Li W, vd. 18\% Efficiency organic solar cells. Sci Bull 2020;65:272-5.

[3] Kurt H, Jia J, Shigesato Y, Ow-Yang CW. Tuning hole charge collection efficiency in polymer photovoltaics by optimizing the work function of indium tin oxide electrodes with solution-processed LiF nanoparticles. J Mater Sci Mater Electron 2015;26:9205-12.

[4] Mingebach M, Deibel C, Dyakonov V. Built-in potential and validity of the Mott-Schottky analysis in organic bulk heterojunction solar cells. Phys Rev B - Condens Matter Mater Phys 2011;84:1-4.

[5] Deledalle F, Kirchartz T, Vezie MS, CampoyQuiles M, Shakya Tuladhar P, Nelson J, vd. Understanding the Effect of Unintentional Doping on Transport Optimization and Analysis in Efficient Organic Bulk-Heterojunction Solar Cells. Phys Rev X 2015;5:011032.

[6] Nyman M, Dahlström S, Sandberg OJ, Österbacka R. Unintentional Bulk Doping of PolymerFullerene Blends from a Thin Interfacial Layer of $\mathrm{MoO}_{3}$. Adv Energy Mater 2016;6:1600670.

[7] Kirchartz T, Gong W, Hawks SA, Agostinelli T, MacKenzie RCI, Yang Y, vd. Sensitivity of the
Mott-Schottky Analysis in Organic Solar Cells. J Phys Chem C 2012;116:7672-80.

[8] Dibb GFA, Muth M-A, Kirchartz T, Engmann S, Hoppe H, Gobsch G, vd. Influence of doping on charge carrier collection in normal and inverted geometry polymer:fullerene solar cells. Sci Rep 2013;3:3335.

[9] Khabbaz Abkenar S, Tufani A, Ince G, Kurt H, Turak A, Ow-Yang CW. Transfer Printing Gold Nanoparticle Arrays by Tuning the Surface Hydrophilicity of Thermo-Responsive Poly Nisopropylacrylamide (pNIPAAm). Nanoscale 2017.

[10] Kurt H. Investigating the effects of nanostructured dielectric lithium fluoride and plasmonic gold interlayers in organic photovoltaics, including the use of in-situ impedance spectroscopy. Sabanci University, 2016.

[11] Kurt H, Ow-Yang CW. Impedance spectroscopy analysis of the photophysical dynamics due to the nanostructuring of anode interlayers in organic photovoltaics. Phys Status Solidi Appl Mater Sci 2016.

[12] Li HH. Refractive index of alkali halides and its wavelength and temperature derivatives. J Phys Chem Ref Data 1976;5:329.

[13] Rakic AD, Djurišic AB, Elazar JM, Majewski ML. Optical Properties of Metallic Films for VerticalCavity Optoelectronic Devices. Appl Opt 1998;37:5271.

[14] Kurt H, Alpaslan E, Yildiz B, Taralp A, Ow-Yang $\mathrm{CW}$. Conformation-mediated Förster resonance energy transfer (FRET) in blue-emitting polyvinylpyrrolidone (PVP)-passivated zinc oxide (ZnO) nanoparticles. J Colloid Interface Sci 2017;488:348-55. 